\title{
UTILIZAÇÃo DO ELUATO DE SANGUE DESSECADO EM PAPEL DE FILTRO NO DIAGNÓSTICO SOROLÓGICO DA TOXOPLASMOSE CAPRINA*
}

\author{
USE OF DRIED BLOOD SAMPLE FOR SEROLOGICAL DIAGNOSIS OF \\ TOXOPLASMOSIS IN GOATS
}

Maria Terezinha BAHIA'; Ricardo Wagner de Almeida VITOR²; George Luiz Lins Machado COELHO; Rogerio Pinheiro CALDAS ${ }^{4}$; Carlos Mauricio Figueiredo ANTUNES ${ }^{2}$; Cléa de Andrade CHIARI ${ }^{2}$

\begin{abstract}
RESUMO
Foi realizada pesquisa de anticorpos anti-Toxoplasma gondii em 183 amostras de sangue dessecado em papel de filtro utilizando as reações de imunofluorescência indireta ELISA e dot-ELISA, tomando como referência os resultados obtidos nos soros. A análise dos resultados demonstrou que papéis com sangue dessecado podem ser conservados por um período mínimo de 45 dias à temperatura ambiente e por seis meses a $4^{\circ} \mathrm{C}$, desde que mantidos livres de umidade pela utilização de agentes dessecantes como a sílica-gel. A reprodutibilidade das reações, avaliada por meio da curva dos títulos de anticorpos no decorrer do tempo após a coleta do sangue em papéis de filtro, demonstrou uma concordância de 97 a 100\% entre os resultados obtidos nos soros e eluatos. Os títulos de anticorpos permaneceram estáveis durante o período observado. Os resultados obtidos com eluato de sangue dessecado foram semelhantes na RIFI, ELISA e dot-ELISA, indicando que qualquer uma das três reações pode ser utilizada em eluatos de sangue dessecado para o diagnóstico da toxoplasmose caprina.
\end{abstract}

UNITERMOS: Coleta de amostras sangüíneas; Toxoplasmose; Caprinos

\section{INTRODUÇÃO}

A indicação do método mais adequado para coleta de sangue em trabalho de campo é extremamente importante, principalmente em levantamentos sorológicos. Em inquérito epidemiológico realizado em grande população ou em área geográfica de difícil acesso, é fundamental a utilização de métodos de coleta que sejam adequados e de fácil execução. A coleta de sangue em papel oferece a vantagem de a amostra poder ser acondicionada à temperatura ambiente, ser transportada por longas distâncias sem exigir separação imediata do soro. Por essas razões, o emprego do papel de filtro na coleta do sangue, para fins de estimativa de prevalência de doenças parasitárias, é encontrado em grande número de trabalhos 6.12,13,17. A análise desses trabalhos mostra que são vários os fatores que podem influenciar a preservação de imunoglobulinas em sangue dessecado em papel de filtro, entre eles a temperatura, a umidade, as técnicas sorológicas utilizadas, a população alvo e os níveis de anticorpos presentes nessa população.
Eluatos de sangue dessecado em papel de filtro (SDPF) já foram utilizados em levantamento sorológico da toxoplasmose caprina ${ }^{2}$, entretanto os autores não testaram a reprodutibilidade dos resultados obtidos nos eluatos de SDPF comparativamente aos do soro. Posteriormente foi demonstrada, também em estudo da toxoplasmose caprina ${ }^{7}$, uma queda significativa nos títulos de anticorpos obtidos nos eluatos de SDPF, ensaiados através da reação de imunofluorescência indireta, em relação aos obtidos no soro. Os autores concluíram pela inadequação do emprego do eluato de SDPF no diagnóstico sorológico para levantamentos da toxoplasmose em rebanho caprino.

Este trabalho objetiva avaliar o uso de eluato de sangue dessecado em papel de filtro para inquéritos sorológicos da toxoplasmose caprina, estipulando condições de conservação adequadas, em relação à sensibilidade obtida no soro, através da reação de imunofluorescência indireta e das reações imunoenzimáticas ELISA e dot-ELISA.

1 -Doutor - Universidade de Alfenas - MG

2 -Doutor - Universidade Federal de Minas Gerais - MG

3-Mestre - Universidade Federal de Ouro Preto - MG

4 -Mestre - CAPRILEITE - Belo Horizonte - MG

"Trabalho financiado pelo CNPq, FAPEMIG e PRPq - UFMG 


\section{MATERIAL E MÉTODO}

1. Animais utilizados: as amostras de sangue foram coletadas de caprinos de diferentes idades, sexos e raças, procedentes de cinco criatórios localizados na região periurbana de Belo Horizonte, Minas Gerais.

2. Coleta do sangue: os animais foram submetidos à punção venosa e parte das amostras de sangue foi utilizada para obtenção do soro e parte distribuída em papéis de filtro Whatman $\mathrm{n} \otimes 4$, que foram transportadas para o laboratório em frascos contendo sílica-gel.No laboratório o papel foi picotado em discos de $6 \mathrm{~mm}$ de diâmetro e acondicionado em sacos plásticos, que foram colocados em frascos contendo agente dessecante.

3. Experimento I: foram utilizadas 18 amostras, colhidas em duplicata e conservadas à temperatura ambiente e a $4^{\circ} \mathrm{C}$, até a hora do exame. Todas as amostras foram codificadas e o estudo realizado de maneira cega.

4. Experimento II: para a avaliação da reprodutibilidade das reações realizadas em eluato de sangue dessecado em papel de filtro, no decorrer do tempo, foi coletada uma amostra de 165 animais. Foi utilizada a metodologia anteriormente citada e o papel com sangue dessecado mantido a $4^{\circ} \mathrm{C}$ em presença da sílica-gel. Os exames foram realizados no $\mathrm{I}^{\circ}, 7^{\circ}$, $15^{\circ}, 30^{\circ}$ e $60^{\circ}$ dia após a coleta (DAC), e com aproximadamente $10 \%$ da amostra ( 18 amostras) seis meses após a coleta. Todas as amostras foram codificadas e o estudo realizado de maneira cega. Aproximadamente $10 \%$ da amostra (17 amostras) foram coletados em duplicata para controle técnico.

A diluição do sangue dessecado em papel foi calculada de acordo com ALVAREZ et al.'(1971), sendo os discos diluídos em tampão fosfato $\mathrm{pH}$ 7,2 (PBS) até atingir a concentração correspondente à diluição de 1:4 do soro. O material permaneceu sob agitação por $30 \mathrm{~min}$. à temperatura ambiente e em seguida foi titulado utilizando-se o mesmo procedimento adotado para o soro.

\section{Reações utilizadas nos experimentos I e II:}

A) Reação de imunofluorescência indireta (RIFI): esta reação foi executada de acordo com a técnica de CAMARGO ${ }^{5}$ (1964), utilizando taquizoítos de cepa $\mathrm{N}^{14}$ do Toxoplasma gondii como antígeno. $\mathrm{O}$ conjugado foi obtido através da marcação de uma anti-IgG caprina com isotiocianato de fluoresceína. A diluição de $1: 16$ foi considerada discriminante de reações positivas e negativas ${ }^{7}$.

B) Reações imunoenzimáticas ELISA e dot-ELISA: para estas reações foi utilizada como antígeno uma suspensão de taquizoítos de Toxoplasma gondii(cepa N) obtida de exudato peritoneal de camundongos, purificada por lavagens sucessivas com PBS e tratada por ultra-som, por três períodos de 1 min., a 40 Hertz.

A reação imunoenzimática ELISA foi realizada de acordo com a técnica de VOLLER et al. ${ }^{15}$ (1976), utilizando como conjugado uma anti-IgG caprina marcada com peroxidase e como substrato ortofenilediamino. As leituras das reações foram feitas em leitor de ELISA (Bio-Rad - Mod. 2550) utilizando filtro de 492 nanômetros, e os resultados expressos em valores de absorbância. A reação foi considerada positiva quando a leitura em densidade óptica foi maior do que a média somada a duas vezes o desvio padrão do valor obtido em densidade óptica para no mínimo 10 soros de animais não reagentes, testados em paralelo aos soros avaliados ${ }^{9}$.

A reação imunoenzimática dot-ELISA foi realizada apenas no experimento II, tendo sido realizada seis meses após a coleta em 134 das 165 amostras. A reação foi realizada de acordo com a técnica de HAWEKES et al. ${ }^{10}$ (1982), modificada, utilizando como conjugado uma anti-IgG caprina marcada com fosfatase alcalina e como substrato 5-bromo-4chloro-indolyl-phosphate/nitro blue tetrazolium. A leitura foi realizada com a observação visual do aparecimento ou não de um precipitado de coloração violácea.

Foi considerada, como discriminante de reações positivas e negativas, a diluição de 1:64.

O teste qui-quadrado foi utilizado para pesquisar a existência de diferenças estatisticamente significativas entre as proporções calculadas ${ }^{3}$. Foram calculados os índices de copositividade, co-negatividade ${ }^{4}$ e concordância de YOUNDEN $^{16}$ (1950) (J), tomando-se os valores obtidos nos soros como referência.

A análise da reprodutibilidade das reações nos eluatos de sangue dessecado em papel de filtro foi feita utilizando os testes de regressão linear e correlação de Pearson ${ }^{3}$, para comparar os resultados obtidos nos soros e nos eluatos de sangue dessecado no $1^{\mathbb{Q}}$ dia após a coleta (DAC). Em seguida foi utilizado um modelo de regressão linear múltipla com variáveis "dummies", de acordo com a seguinte equação":

$$
\begin{gathered}
\mathrm{Y}=\mathrm{a}+\mathrm{B}_{1} \mathrm{D}_{1}+\mathrm{B}_{2} \mathrm{D}_{2}+\mathrm{B}_{3} \mathrm{D}_{3}+\mathrm{B}_{4} \mathrm{D}_{4} \\
\mathrm{Y}=\text { título no eluato } \\
\mathrm{X}=\text { título no eluato no }{ }^{\circ} \mathrm{DAC}
\end{gathered}
$$


BAHIA, M.T.; VITOR, R.W.A.; COELHO, G.L.L.M.; CALDAS, R.P.; ANTUNES, C. M.F.; CHIARI, C. A. Utilização do eluato de sangue dessecado em papel de filtro no diagnóstico sorológico da toxoplasmose caprina. Braz. J. vet. Res. anim. Sci., Săo Paulo, v.32, n.2, p.83-8, 1995.

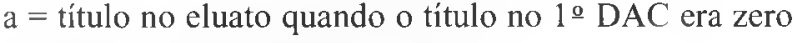
$\mathrm{B}_{1}, \mathrm{~B}_{2}$ e $\mathrm{B}_{3}=$ coeficientes de regressão

$\mathrm{D}_{1}, \mathrm{D}_{2}$ e $\mathrm{D}_{3}=$ variáveis "dummies". Os valores das variáveis "dummies" foram, de acordo com o modelo: 1 DAC, $\mathrm{D}_{1}=$ $1, \mathrm{D}_{2}=0, \mathrm{D}_{3}=-1, \mathrm{D}_{4}=1 ; 7^{\circ} \mathrm{DAC}, \mathrm{D}_{1}=-1, \mathrm{D}_{2}=0, \mathrm{D}_{3}=1$, $\mathrm{D}_{4}=1 ; 15^{\circ} \mathrm{DAC}, \mathrm{D}_{1}=0, \mathrm{D}_{2}=-1, \mathrm{D}_{3}=1, \mathrm{D}_{4}=1 ; 30^{\circ} \mathrm{DAC}$, $\mathrm{D}_{1}=0, \mathrm{D}_{2}=1, \mathrm{D}_{3}=1, \mathrm{D}_{4}=1 ; 60^{\mathrm{o}} \mathrm{DAC}, \mathrm{D}_{1}=0, \mathrm{D}_{2}=0$, $\mathrm{D}_{3}=0, \mathrm{D}_{4}=-4$.

\section{RESULTADOS}

No experimento I, realizado com o objetivo de avaliar a forma de conservação dos papéis embebidos em sangue, foi observada uma concordância de $100 \%$ entre os resultados obtidos por meio da RIFI e da ELISA em 18 soros e eluatos de sangue dessecado em papel de filtro conservados à temperatura ambiente ou a $4^{\circ} \mathrm{C}$, em sacos plásticos lacrados, em presença de sílica-gel.

No experimento II a análise dos resultados obtidos através da RIFI e da ELISA, nas 165 amostras, mostrou não existir diferença significativa entre a proporção de resultados positivos obtidos em soros e eluatos até o $60^{\circ}$ dia após a coleta (DAC) (Tab. 1,2).

Os resultados de $10 \%$ da amostra (18 animais), ensaiada através da RIFI e da ELISA, mostraram que a reatividade dos eluatos não foi alterada mesmo seis meses após a coleta.
Resultados semelhantes foram observados, quando 134 amostras de sangue dessecado, conservadas durante seis meses a $4^{\circ} \mathrm{C} \mathrm{em}$ frascos contendo sílica-gel, foram testadas pela reação imunoenzimática dot-ELISA. Na Tab. 3 pode-se observar a alta concordância obtida entre os resultados dos soros e eluatos.

A análise da dispersão dos títulos de anticorpos, das amostras de soros e eluatos de sangue dessecado em papel de filtro ensaiados pela RIFI, por meio da regressão linear, mostrou existir uma correlação significativa $(r=0,94)$ entre os títulos de anticorpos observados nos soros e nos eluatos no $1^{\circ} \mathrm{DAC}$ (Fig.1) e evidencia não haver diferença significativa entre os títulos de anticorpos obtidos. A comparação dos títulos de anticorpos obtidos entre os eluatos ao $7^{\circ}$ ․ $15^{\circ}$, $30^{\circ}$ e $60^{\circ} \mathrm{DAC}$ com o título do eluato no 1 o DAC (referência), utilizando-se o teste de regressão linear múltipla (Fig.2), forneceu valores de $\mathrm{F}$ calculados para os coeficientes de regressão das variáveis indicadoras $(\mathrm{D} 1=-0,89 ; \mathrm{D} 2=-0,017 ; \mathrm{D} 3=0,017 ; \mathrm{D} 4=0,12$ ) e indicou não existir diferença significativa, em nível de confiança de 0,01 , entre os títulos obtidos nos eluatos no decorrer do tempo.

Resultados semelhantes foram observados na ELISA quando comparadas às absorbâncias obtidas nos soros e eluatos no 19 DAC ( Fig. 3). A análise de regressão linear mostrou existir uma correlação significativa $(r=0,91)$ entre as absorbâncias.

TABELA 1

Distribuição de resultados positivos (POS) e negativos (NEG), índices de co-positividade (icp), co-negatividade (icn) e concordância (J), obtidos por meio da reação de imunofluorescência indireta, realizada em 164 soros de caprinos e eluatos de sangue dessecado em papel de filtro (SDPF), conservados por diferentes períodos de tempo a $4^{\circ} \mathrm{C}$ em sacos plásticos contendo sílica-gel. Belo Horizonte - MG, março a junho de 1992.

\begin{tabular}{|c|c|c|c|c|c|c|c|c|}
\hline \multirow{2}{*}{$\begin{array}{l}\text { DIA APÓS } \\
\text { A COLETA }\end{array}$} & \multicolumn{2}{|c|}{ SORO } & \multicolumn{2}{|c|}{ ELUATO DE SDPF } & \multirow[t]{2}{*}{ icp } & \multirow[t]{2}{*}{ jen } & \multirow[t]{2}{*}{$\mathrm{J}$} & \multirow[t]{2}{*}{$\mathrm{X}^{2}{ }_{\mathrm{l}} \mathrm{gl}$} \\
\hline & $\overline{\mathrm{POS}}$ & NEG & POS & NEG & & & & \\
\hline $01^{\circ}$ & 110 & 54 & 109 & 55 & 0,99 & 0,96 & 0,95 & 0,0 \\
\hline $07^{\circ}$ & 110 & 54 & 108 & 56 & 0,99 & 0,95 & 0,94 & 0,25 \\
\hline $15^{\circ}$ & 110 & 54 & 107 & 57 & 0,99 & 0,93 & 0,92 & 0,8 \\
\hline $30^{0}$ & 110 & 54 & 107 & 57 & 0,99 & 0,95 & 0,94 & 0,8 \\
\hline $60^{\circ}$ & 110 & 54 & 108 & 56 & 0,99 & 0,95 & 0,94 & 0,25 \\
\hline
\end{tabular}

TABELA 2

Distribuição de resultados positivos (POS) e negativos (NEG), índices de co-positividade (icp), co-negatividade (icn) e concordância (J), obtidos com a reação imunoenzimática ELISA, realizada em 165 soros de caprinos e eluatos de sangue dessecado em papel de filtro (SDPF), conservados por diferentes períodos de tempo a $4^{\circ} \mathrm{C}$ am sacos plásticos contendo sílica-gel. Belo Horizonte - $\mathrm{MG}$, março a junho de 1992.

\begin{tabular}{|c|c|c|c|c|c|c|c|c|}
\hline \multirow{2}{*}{$\begin{array}{l}\text { DIA APÓS } \\
\text { A COLETA }\end{array}$} & \multicolumn{2}{|c|}{ SORO } & \multicolumn{2}{|c|}{ ELUATO DE SDPF } & \multirow[t]{2}{*}{ icp } & \multirow[t]{2}{*}{ icn } & \multirow[t]{2}{*}{$\mathrm{J}$} & \multirow[t]{2}{*}{$\mathrm{X}^{2}{ }_{1} \mathrm{gl}$} \\
\hline & $\overline{\mathrm{POS}}$ & NEG & $\overline{\text { POS }}$ & $\overline{\text { NEG }}$ & & & & \\
\hline 019 & 108 & 57 & 109 & 56 & 0,99 & 1,00 & 0,99 & 0,0 \\
\hline $07^{\circ}$ & 108 & 57 & 109 & 56 & 0,99 & 1,00 & 0,99 & 0,0 \\
\hline $15^{\circ}$ & 108 & 57 & 107 & 58 & 1,00 & 0,98 & 0,95 & 0,0 \\
\hline $30^{\circ}$ & 108 & 57 & 108 & 57 & 0.99 & 0,98 & 0,97 & 0,5 \\
\hline $60^{\circ}$ & 108 & 57 & 109 & 56 & 0,99 & 1,00 & 0,99 & 0,0 \\
\hline
\end{tabular}


BAHIA, M.T.; VITOR, R.W.A.; COELHO, G.L.L.M.; CALDAS, R.P.; ANTUNES, C. M. F.; CHIARI, C. A. Utilização do eluato de sangue dessecado em papel de filttro no diagnóstico sorológico da toxoplasmose caprina. Braz. J. vet. Res. anim. Sci., Săo Paulo, v.32, n.2, p.83-8, 1995

\section{TABELA 3}

Distribuição cruzada de reações positivas (POS) e negativas (NEG) em soros de caprino e eluatos de sangue dessecado em papel de filtro, conservados durante seis meses em frascos contendo sílicagel a temperatura de $4^{\circ} \mathrm{C}$, por meio da reação imunoenzimática dotELISA. Belo Horizonte - MG, outubro de1992.

\begin{tabular}{|c|c|c|c|c|}
\hline & & \multicolumn{2}{|c|}{ ELUATO } & \multirow{2}{*}{ TOTAL } \\
\hline & & POS & NEG & \\
\hline \multirow{2}{*}{ SORO } & POS & 85 & 01 & 86 \\
\hline & NEG & 0 & 48 & 48 \\
\hline \multicolumn{2}{|c|}{ TOTAL } & 85 & 49 & 134 \\
\hline \multicolumn{2}{|c|}{$X^{2}{ }_{1} g l=0,0$} & $c p=0,9$ & $\mathrm{icn}=1,00$ & $\mathrm{~J}=0,99$ \\
\hline
\end{tabular}

RECÍPROCA DO TÍTULO 1000 - ELUATO DE SDPF

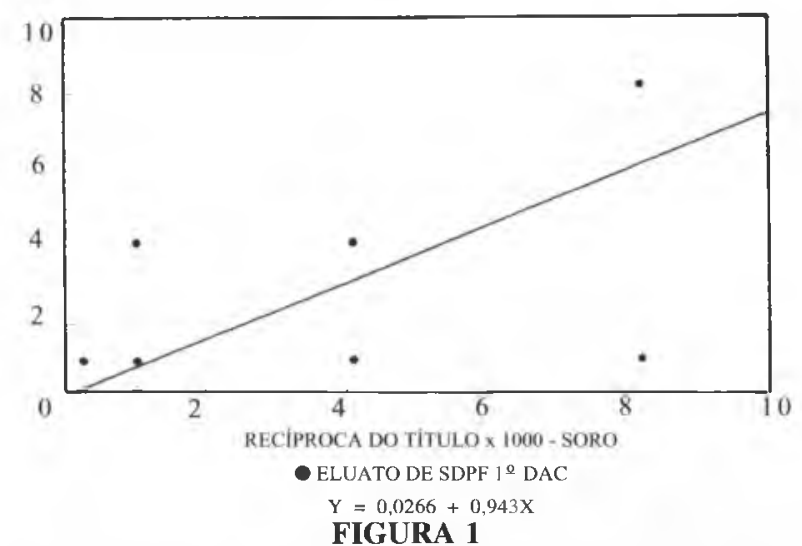

Dispersão da recíproca dos títulos de anticorpos obtidos pela reação de imunofluorescência indireta em soros e eluatos de sangue dessecado em papel de filtro (SDPF) no 1 a dia após a coleta (DAC) de 164 caprinos e a equação da reta pelo teste de regressão linear.

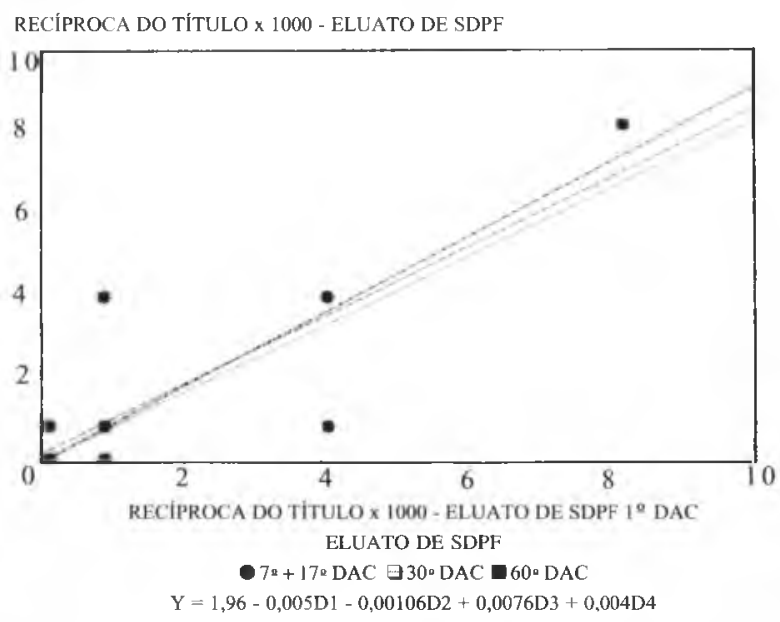

FIGURA 2

Dispersão da recíproca dos títulos de anticorpos obtidos pela reação de imunofluorescência indireta em eluatos de sangue dessecado em papel de filtro (SDPF) no $1^{0}$ dia após a coleta (DAC) e eluatos no $7 \circ, 15^{\circ}, 30^{\circ}$ e $60^{\circ}$ DAC, coletados de 164 caprinos $\mathrm{e}$ a equação da reta pelo teste de regressão linear mútipla.

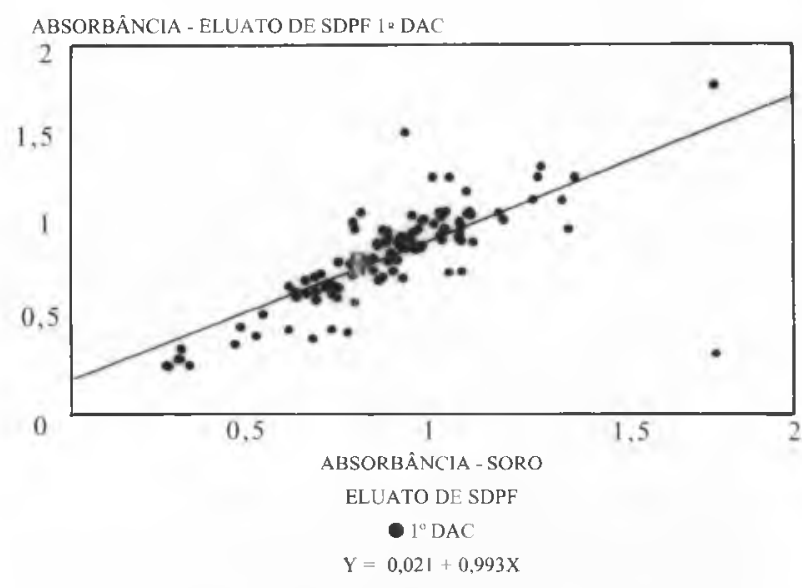

FIGURA 3

Dispersão da absorbância obtida pela ELISA em soros e eluatos de sangue dessecado em papel de filtro (SDPF) no $1^{10}$ dia após a coleta das amostras de 165 caprinos e a equação da reta pelo teste de regressão linear.

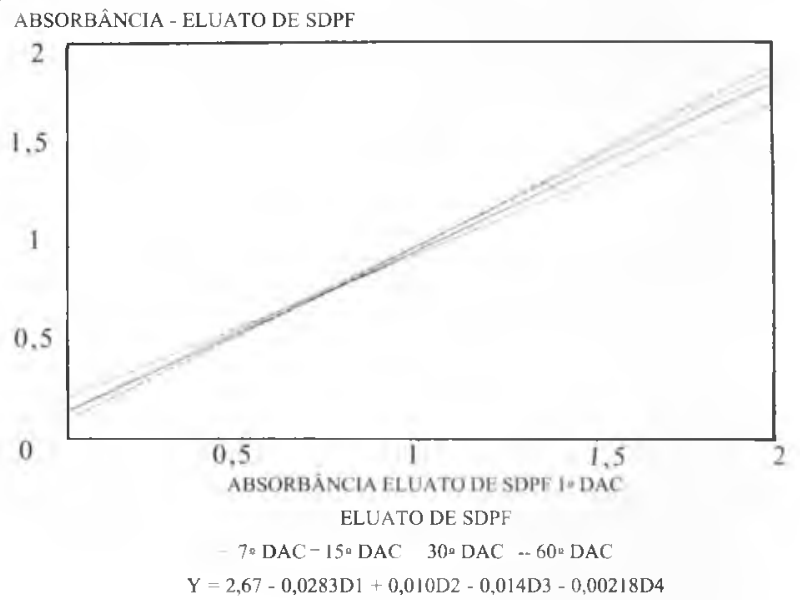

FIGURA 4

Dispersão da absorbância obtida pela ELISA em eluatos de sangue dessecado em papel de filtro (SDPF) no $1^{\circ}$ dia após a coleta (DAC) e eluatos no $7^{\circ}, 15^{\circ}, 30^{\circ}$ e $60^{\circ}$ DAC, coletados de 165 caprinos e a equação da reta pelo teste de regressão linear múltipla.

A comparação entre as absorbâncias observadas nos eluatos até o $60^{\circ} \mathrm{DAC}$, tomando-se os resultados do $1 \cong \mathrm{DAC}$ como referência, estão apresentados na Fig. 4. Os valores de F, calculados para os coeficientes de regressão das variáveis indicadoras $(\mathrm{D} 1=0,267 ; \mathrm{D} 2=0,001 ; \mathrm{D} 3=0.001$; $\mathrm{D} 4=$ $0,016)$, indicam não existir diferença significativa na leitura em absorbância no decorrer do tempo de armazenamento do sangue dessecado em papel de filtro.

A dispersão dos títulos de anticorpos entre soros e eluatos. ensaiados através da dot-ELISA, estão apresentados na Fig. 5. A análise de regressão linear e correlação mostrou relação significativa entre os títulos de anticorpos obtidos entre os soros e os eluatos $(r=0,96)$, ou seja, não existe diferença significativa entre a dispersão dos títulos de anticorpos entre soros e eluatos conservados seis meses em presença de agente dessecante. 
RECÍPROCA DO TITULO $\times\lfloor 00()$ - ELUATO DE SDPF

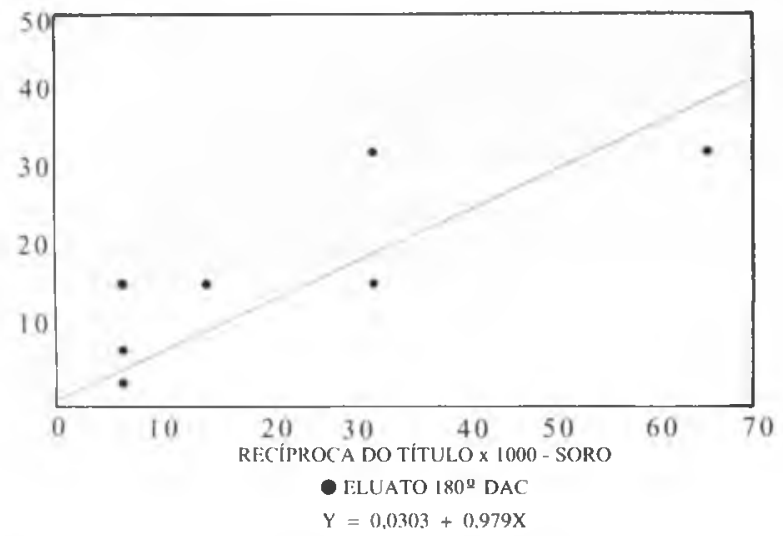

FIGURA 5

Dispersão da recíproca dos títulos de anticorpos obtidos pela reação imunoenzimática dot-ELISA em soros e eluatos de sangue dessecado em papel de filtro (SDPF) no $1^{\circ}$ dia após a coleta das amostras de 134 caprinos e a equação da reta pelo teste de regressão linear.

\section{DISCUSSÃO}

Os resultados mostraram que quando os papéis de filtro embebidos em sangue são mantidos em presença de agentes dessecantes a reatividade da amostra permanece inalterada, quando avaliada pela RIFI, ELISA e dot-ELISA, mesmo quando mantidas à temperatura ambiente por 45 dias.

A alta concordância observada entre os resultados dos soros e eluatos (97 a $99 \%$ até os seis meses) e os índices de copositividade e co-negatividade mostram que as condições de coleta e conservação foram suficientes para a manutenção dos níveis de anticorpos iniciais em todas as técnicas testadas, mostrando que qualquer uma delas pode ser utilizada na toxoplasmose caprina. Os resultados obtidos neste trabalho são mais animadores do que os obtidos em estudo sorológico da toxoplasmose caprina, através da $\operatorname{RIFI}^{7}$, onde foi observada queda significativa de títulos de anticorpos entre o $1^{\circ}$ e o 5 ㅇ DAC. Essas divergências observadas provavelmente estão relacionadas às condições de manutenção do sangue dessecado, pois os autores conservaram os papéis a $-20^{\circ} \mathrm{C}$ em envelopes de papel, portanto, sem controle de umidade. Outros fatores, além da umidade, poderiam ter influenciado as divergências citadas acima, pois, segundo $\mathrm{COELHO}^{8}(1990)$, técnicas sorológicas consideradas mais sensíveis, como a ELISA, são mais adequadas para utilização em eluatos de sangue dessecado em papel de filtro. Devem ser lembrados, ainda, os trabalhos realizados em Malária e doença de Chagas, que mostram uma grande percentagem de negativação em amostras de eluatos, sempre relacionadas com títulos baixos de anticorpos ${ }^{12,17}$. Deve ser ressaltado que na toxoplasmose caprina observa-se uma grande percentagem de níveis baixos de anticorpos. Sendo assim, o sucesso deste experimento não poderia estar ligado a nenhum dos dois fatores citados anteriormente, isto é, aos níveis de anticorpos ou à reação utilizada, mas provavelmente ao método de conservação do sangue dessecado em papel de filtro, pois o controle da umidade parece ser primordial na conservação das imunoglobulinas. Esse fato já havia sido sugerido em estudos sobre a reprodutibilidade da reação de hemaglutinação indireta no diagnóstico da doença de Chagas com o emprego de eluatos ${ }^{17}$. Esses autores concluíram que quanto maior a umidade relativa do ar e mais alta a temperatura, menor é o tempo de conservação dos títulos de anticorpos no papel de filtro.

\section{CONCLUSÃO}

Os dados obtidos permitem concluir que o eluato de sangue dessecado em papel de filtro pode ser utilizado no diagnóstico sorológico da toxoplasmose caprina, já que a reatividade inicial da amostra é conservada mesmo quando os níveis iniciais de imunoglobulinas são baixos, desde que o material seja conservado livre de umidade. Além disto, o papel com sangue dessecado, mantido livre de umidade, pode ser conservado até o $45^{\circ} \mathrm{DAC}$ à temperatura ambiente (não foi testado além desse período), tempo suficiente para a execução da sorologia ou o transporte ao laboratório; ou por um período mínimo de seis meses a $4^{\circ} \mathrm{C}$, sem perda de reatividade.

\section{AGRADECIMENTOS}

Ao professor Paul Williams pela revisão do texto em inglês. A sra. Rosálida Estevam Nazar Lopes e ao sr. José Luiz de Faria pelos auxílios técnicos.

\section{SUMMARY}

Eluates of 183 dried caprine blood samples on filter paper were tested for anti-Toxoplasma gondii antibodies, using IFA, ELISA and dot-ELISA, and compared with results obtained by direct observations on comparable sera, usin the same tests.

The results has showed that papers with dried blood can be preserved for up to 45 days at room temperature and for six months at $4^{\circ} \mathrm{C}$, provided they are protected against humid conditions by using desiccating agents such as silica-gel. Comparison between serum and eluate reactions revelated $97-100 \%$ correspondance. The antibody titers remained constant throughout the study period.

UNITERMS: Blood specimen collection; Toxoplasmosis; Goats 
BAHIA, M.T.; VITOR, R.W.A.; COELH@, G.L.L.M.; CALDAS, R.P.; ANTUNES, C. M. F.; CHIARI, C. A. Utilização do eluato de sangue dessecado em papel de filtro no diagnóstico sorológico da toxoplasmose capriná. Braz. J. vet. Res. anim. Sci., São Paulo, v.32, n. 2, p.83-8, 1995

\section{REFERÊNCIAS BIBLIOGRÁFICAS}

I-ALVAREZ, M.; RISSIO, M.; MARTINI, G.J.W.; ORREGO, L.A.; CERISOLA, J.A. Recolección de sangre en papel para diagnóstico de infección chagásica por inmunofluorescencia. Boletín Chileno de Parasitología, v.26, p.2-6, 1971.

2-AMARAL, V.; SANTOS, S.M.; REBOUÇAS, M.M. Sobre a prevalência de anticorpos antitoxoplasma em soros de caprinos e ovinos procedentes, respectivamente dos Estados da Bahia e Rio Grande do Sul, Brasil. O Biológico, São Paulo, v.44, p.331-40, 1978.

3-ARMITAGE, P.Statistical methods in medical research London, Blackwell, 1987.

4-BUCK, A.A.; GART, J.J. Comparison of a screening test and a reference test in epidemiologic studies. American Journal of Epidemiology, v.83, p.586 - 92, 1965.

5-CAMARGO, M. Estudo comparativo das reações de Sabin-Feldman e de imunofluorescência indireta para toxoplasmose em 1000 soros humanos, comportamento anômalo de alguns soros. Revista do Instituto Adolfo Lutz, v.24, p.1-26, 1964.

6-CAMARGO, M.E.; SILVA, G.R.; CASTILHO, E.A.; SILVEIRA, A.C. Inquérito sorológico da prevalência de infeç̧ão chagásica no Brasil. Revista do Instituto de Medicina Tropical de São Paulo, v.26, p. 192-204, 1984.

7-CHIARI, C.A.; LIMA, W.S.; ANTUNES,C.M.F.; LIMA, J.D. Soro-epidemiologia da toxoplasmose caprina em Minas Gerais, Brasil. Arquivo Brasileiro de Medicina Veterinária e Zootecnia, v.39, p.587-609, 1987.

8-COELHO, G.L.L.M. Avaliação da sorologia para inquéritos epidemiológicos da infecção pelo Trypanosoma cruzi. Belo Horizonte, UFMG, 1990. Dissertação (Mestrado) - Instituto de Ciências Biológicas, Universidade Federal de Minas Gerais.

9-GUSMÃO, R.; REZENDE, J.M.; RASSI, A.; GAM, A.; NEVA, F. Antibody levels to Trypanosoma cruzi in infected patients with and without evidence of chronic Chagas Disease. American Journal of Tropical Medicine and Hygiene,v. 31, p.452-8, 1982.
10-HAWEKES, R.; NIDAY, E.; GORDON, J. A dotimmunobinding assay for monoclonal and other antibodies. Analytical Biochemistry, v.119, p.119-42, 1982.

11 -KLEINBAUM, D.G.; KUPPER, L.L.Applied regression analysis and other multivariable methods. Massachusetts, Duxbury Press, 1978.

12-LOBEL, H.O.; NAJERA, A.J.;CH'EN, W.I.; NUNROE, P.; MATHEWS, H. Seroepidemiologic investigations of malaria in Guyana. Journal of Tropical Medicine and Hygiene, v.79, p.275-84, 1976.

13-MARINKELLE, C.J.; SANCHES, N.; GROEL, M. Recomendaciones para el almacenamiento de sueros absorbidos en papel de filtro bajo condiciones rurales, para el diagnóstico de infección chagásica con la prueba de inmmunofluorescencia. Revista do Instituto de Medicina Tropical de São Paulo, v.20, p.112-4, 1978.

14-NOBREGA, P.; TRAPP, E.E.; GIOVANNON1, M. Toxoplasmose epizoótica em coelhos. I. Ação da sulfadiazina. Ciência e Cultura, v.4, p.134-5, 1952.

15-VOLLER, A; BIDWELL, D.E.; BARTLETT, A. Enzyme immunoassays in diagnostic medicine. Theory and practice. Bulletin of the World Health Organization, v.53, p.55-65, 1976.

16-YOUDEN, W.J. Index for rating diagnostic tests. Cancer, v.3, p.32-5, 1950.

17-ZICKER, F.; SMITH, P.G.; LUQUETTI, A.D.; OLIVEIRA, O.S. Mass screening of Trypanosoma cruziinfections using the immunofluorescence ELISA and haemaglutination tests on serum samples and blood eluates from filter-paper. Bulletin de l'Organisation Mondiale de la Santé, v.68, p.465-71, 1990.
Recebido para publicação em 02/09/93 Aprovado para publicação em 03/08/94 